University of Nebraska - Lincoln

DigitalCommons@University of Nebraska - Lincoln

Public Health Resources

Public Health Resources

2006

\title{
Identification of an Epithelial-Specific Enhancer Regulating ESX Expression
}

Richard M. Neve

Cancer Research Institute, University of California San Francisco, Box 0808, San Francisco, CA

94143-0808, USA

Hema Parmar

Cancer Research Institute, University of California San Francisco, Box 0808, San Francisco, CA

94143-0808, USA

Cliff Amend

Buck Institute for Age Research, 8001 Redwood Boulevard, Novato, CA 94945, USA

Chira Chen

Cancer Research Institute, University of California San Francisco, Box 0808, San Francisco, CA 94143-0808, USA

Angie Rizzino

Eppley Institute for Research in Cancer and Allied Diseases, University of Nebraska Medical Center, Omaha, NE 68198-6805, USA

See next page for additional authors

Follow this and additional works at: https://digitalcommons.unl.edu/publichealthresources

Part of the Public Health Commons

Neve, Richard M.; Parmar, Hema; Amend, Cliff; Chen, Chira; Rizzino, Angie; and Benz, Christopher C., "Identification of an Epithelial-Specific Enhancer Regulating ESX Expression" (2006). Public Health Resources. 71.

https://digitalcommons.unl.edu/publichealthresources/71

This Article is brought to you for free and open access by the Public Health Resources at DigitalCommons@University of Nebraska - Lincoln. It has been accepted for inclusion in Public Health Resources by an authorized administrator of DigitalCommons@University of Nebraska - Lincoln. 


\section{Authors}

Richard M. Neve, Hema Parmar, Cliff Amend, Chira Chen, Angie Rizzino, and Christopher C. Benz 


\title{
Identification of an epithelial-specific enhancer regulating ESX expression
}

\author{
Richard M. Neve ${ }^{b, c, *}$, Hema Parmar ${ }^{b}$, Cliff Amend ${ }^{a}$, Chira Chen ${ }^{b}$, \\ Angie Rizzino ${ }^{\mathrm{d}}$, Christopher C. Benz ${ }^{\mathrm{a}}$ \\ a Buck Institute for Age Research, 8001 Redwood Boulevard, Novato, CA 94945, USA \\ ${ }^{\mathrm{b}}$ Cancer Research Institute, University of California San Francisco, Box 0808, San Francisco, CA 94143-0808, USA \\ ${ }^{\mathrm{c}}$ Lawrence Berkeley National Laboratory, 717 Potter Street, Berkeley, CA 94710-2722, USA \\ ${ }^{\mathrm{d}}$ Eppley Institute for Research in Cancer and Allied Diseases, University of Nebraska Medical Center, Omaha, NE 68198-6805, USA
}

Received 21 June 2005; received in revised form 30 September 2005; accepted 2 October 2005

Available online 15 December 2005

Received by A.J. van Wijnen

\begin{abstract}
The Ets transcription factor, ESX, exhibits a unique pattern of epithelial-restricted expression and transactivates genes involved in epithelial differentiation and cancer. The aim of this study was to determine the underlying genetic basis for epithelial-specific expression of ESX. We have identified a 30bp ESX enhancer sequence (EES) approximately $3 \mathrm{~kb}$ upstream of the proximal promoter. This region displays enhancer activity in an epithelial-specific manner and deletion of this region abrogates ESX gene transcription. An EES binding protein complex (EBC) was identified through electrophoretic mobility shift assays whose degree of EES binding correlated well with endogenous ESX levels in epithelial cells and was regulated by epithelial differentiation. Understanding the regulation of this element will lend insight into mechanisms of epithelial differentiation and the etiology of breast cancer and may provide novel targets for cancer therapeutic intervention.
\end{abstract}

\section{Introduction}

Ets transcription factors regulate gene expression during a number of biologic processes including proliferation, transformation, differentiation, morphogenesis and development. The Ets family comprises more than 40 members, many of which have been shown to be involved in the development and homeostasis of cell lineages as well as in the genesis of human cancer (Dittmer and Nordheim, 1998; Sharrocks, 2001). Null mutations of various Ets factors

Abbreviations: RA, retinoic acid; Act. D, actinomycin D; TGF- $\beta$, transforming growth factor beta; TGF- $\beta$ RII, type II TGF-beta-receptor; MAPK, mitogen-activated protein kinase; PI3K, phosphoinositide-3 kinase; EMSA, electrophoretic mobility shift assay; hFib, human fibroblasts.

* Corresponding author. Lawrence Berkeley National Laboratory, 717 Potter Street, Berkeley, CA 94710-2722, USA. Tel.: +1 510486 6815; fax: +1 510495 2535.

E-mail address: rmneve@lbl.gov (R.M. Neve). result in embryonic or neonatal lethality indicating a critical role in early development (Remy and Baltzinger, 2000; Ng et al., 2002) whereas genetic translocations of Ets genes are associated with early life cancers and leukemias (Dittmer and Nordheim, 1998). While there has been extensive research into the role of Ets factors in haemopoeitic lineages very little is known about Ets factors in epithelial lineages.

Recently, a number of independent reports identified a novel Ets factor, ESX (also termed Elf3, Jen, Ert and Ese1), which is associated with mammary gland development, carcinogenesis and epithelial differentiation (Andreoli et al., 1997; Oettgen et al., 1997; Tymms et al., 1997; Neve et al., 1998; Chang et al., 1999; Brembeck et al., 2000; Yoshida et al., 2000). ESX is of particular interest as it is found exclusively expressed in terminally differentiated epithelial cells in the mammary gland, colon, trachea, kidney, prostate, uterus, stomach and skin under homeostatic conditions (Andreoli et al., 1997; Oettgen et al., 
1997; Tymms et al., 1997; Neve et al., 1998). A number of genes have been identified as transcriptional targets of $E S X$, including transforming growth factor beta-type-II receptor (TGF- $\beta$ RII) (Choi et al., 1998; Kim et al., 2002), several differentiation-specific markers (Andreoli et al., 1997; Oettgen et al., 1997; Brembeck et al., 2000; Yoshida et al., 2000), MIP3- $\alpha$ (Kwon et al., 2003), nitric oxide synthase (Rudders et al., 2001) and tumour-associated genes (Eckel et al., 2003). ESX is also a putative mediator of inflammatory shock and host defense (Rudders et al., 2001) and it is in response to inflammatory stimuli that ESX expression is induced in non-epithelial cells (Rudders et al., 2001). In breast cancer, ESX expression is significantly correlated with ErbB2 expression, and is a downstream transcriptional target of ErbB2 (Neve et al., 2002).

Here we sought to identify cis-acting elements within the $E S X$ locus that control the epithelial-specific expression of $E S X$. We describe a 30-bp enhancer element approximately 3 $\mathrm{kb}$ upstream of the transcriptional start point that directly controls ESX expression. This ESX enhancer sequence (EES) is regulated in response to differentiation and appears to be positively controlled by an EES binding protein complex (EBC).

\section{Materials and methods}

\subsection{Cell culture and transient transfection assays}

Sk-Br-3 cells were grown in McCoys5A medium supplemented with $10 \%$ fetal calf serum. MCF7 cells were grown in Dulbecco's modified Eagle's medium (DMEM) $1 \mathrm{~g} / \mathrm{L}$ glucose supplemented with $10 \%$ fetal calf serum and $0.01 \mathrm{mg} / \mathrm{ml}$ bovine insulin. MCF10A and MCF12A cells were grown in a 50:50 mix of DMEM/Hams F12 supplemented with $20 \mathrm{ng} / \mathrm{ml} \mathrm{EGF,} 100 \mathrm{ng} / \mathrm{ml}$ cholera toxin, 0.01 $\mathrm{mg} / \mathrm{ml}$ insulin, $50 \mathrm{ng} / \mathrm{ml}$ hydrocortisone and $5 \%$ horse serum. HC11 cells were grown in RPMI medium supplemented with $10 \%$ fetal calf serum, $5 \mu \mathrm{g} / \mathrm{ml}$ insulin and 10 $\mathrm{ng} / \mathrm{ml}$ EGF. Human fibroblasts were maintained in a 50:50 mix of DMEM/Hams F12 supplemented with $5 \mu \mathrm{g} / \mathrm{ml} \mathrm{In-}$ sulin and $10 \%$ fetal calf serum. All cells were grown at 37 ${ }^{\circ} \mathrm{C}$ and $5 \% \mathrm{CO}_{2}$.

Transient transfections were carried out using Effectene (Qiagen) transfection reagent according to manufacturer's instructions. Briefly, cells were grown in 6-well plates and transfected at approximately 50\% confluency. For each well $1 \mu \mathrm{g}$ of the luciferase reporter plasmid and $0.5 \mu \mathrm{g}$ of $\mathrm{LacZ}$ plasmid (internal control) were co-transfected to control for transfection efficiency. After 24 $\mathrm{h}$ cells were washed in phosphate-buffered saline (PBS) and extracted using passive lysis buffer (Promega) and luciferase assays performed with a luciferase assay system (Promega) and luminometer. Beta-galactosidase values were obtained using a chemiluminescent reporter assay system (Tropix Galactolight Assay) and used to normalize luciferase values.

\subsection{Immunochemical techniques}

For immunoblot analysis, cleared cell lysates were electrophoretically resolved on denaturing sodium doedecyl sulphate (SDS)-polyacrylamide gels (4-12\%), transferred to polyvinylidene difluoride (PVDF, Millipore), and probed with specific antisera. The primary antibody to $E S X$ was prepared and purified as in Chang et al. (1997).

\subsection{Northern analysis}

For Northern blotting, total cellular RNA was purified from cells using RNeasy (Qiagen). RNA (20 ug/sample lane) was electrophoresed through $1 \%$ formaldehyde-agarose gels and transferred to nylon membranes. Blots were probed with a cterminal single-stranded PCR-amplified DNA fragment corresponding to the anti-sense strand of the last $400 \mathrm{bp}$ of the $3^{\prime} E S X$ cDNA sequence. After annealing and a final wash at $65^{\circ} \mathrm{C}$ in $0.2 \times \mathrm{SSC}$ the membrane was exposed to film and the autoradiograph developed.

\subsection{Reverse-transcriptase PCR}

RNA was isolated from cells using the RNeasy kit (Quiagen), and semi-quantitative RT-PCR was performed using the Superscript One Step RT-PCR system (Invitrogen). Briefly, the reactions were prepared with $0.5 \mu \mathrm{g}$ total RNA and primers for $E S X$ (forward: 5'-GATCATTGAGCTGCTGGAGAAGGA3', reverse: 5'-GTCCCAGTACTCTTTGCTCAGCTT-3') that yield a 317 bp product. The cDNA was generated at $50{ }^{\circ} \mathrm{C}$ for $30 \mathrm{~min}$. Subsequent denaturation for $2 \mathrm{~min}$ at $94{ }^{\circ} \mathrm{C}$ was followed by 40 cycles of $94{ }^{\circ} \mathrm{C}, 30 \mathrm{~s} ; 56^{\circ} \mathrm{C}, 30 \mathrm{~s} ; 72{ }^{\circ} \mathrm{C}, 45 \mathrm{~s}$. The RT-PCR products were separated on a $0.8 \%$ agarose gel and visualised under UV light.

\subsection{Cell lysates, nuclear extracts and EMSAs}

For preparation of protein lysates, cells were washed in ice cold PBS containing $1 \mathrm{mM}$ phenylmethylsulfonyl fluoride (PMSF) and then with a buffer containing $50 \mathrm{mM}$ HEPES (pH7.5), $150 \mathrm{mM} \mathrm{NaCl}, 25 \mathrm{mM}$ ß-glycerophsphate, $25 \mathrm{mM} \mathrm{NaF}, 5 \mathrm{mM}$ EGTA, $1 \mathrm{mM}$ EDTA, 15 $\mathrm{mM}$ pyrophosphate, $2 \mathrm{mM}$ sodium orthovanadate, $10 \mathrm{mM}$ sodium molybdate, leupeptin $(10 \mu \mathrm{g} / \mathrm{ml})$, aprotinin $(10 \mu \mathrm{g} /$ $\mathrm{ml}$ ) and $1 \mathrm{mM}$ PMSF. Cells were extracted in the same buffer containing 1\% Nonidet-P40. Lysates were then clarified by centrifugation and frozen at $-80{ }^{\circ} \mathrm{C}$. Protein concentrations were determined using the Bio-Rad protein assay kit.

Nuclear extracts were prepared using the method of Dignam et al. (1983). Electrophoretic mobility shift assays (EMSAs) were performed using $5 \mu \mathrm{g}$ of nuclear extract and $3 \times 10^{4} \mathrm{cpm}$ of end-labelled double stranded oligonucleotides (EEC sense; 5'-GAAGCCGGTTCTCCCACATTCCTGG-GTGAG-3', antisense; 5'-CTCACCCAGGAATGTGGGAGAACCGGCTTC$\left.3^{\prime}\right)$. Binding reactions were performed at room temperature for $15 \mathrm{~min}$. Reactions were carried out in $20 \mu \mathrm{l}$ of DNA 
Table 1

Oligonucleotide sequences used for cloning of various ESX reporter constructs

\begin{tabular}{cccl}
\hline Construct & H/ & $5^{\prime \prime}$ & Oligonucleotide sequence \\
& M & $3^{\prime}$ & \\
\hline-347 & M & $5^{\prime}$ & CCGCCTCGAGTCAGCCCTGGCCAGGCCCCCAGG \\
Luc & & $3^{\prime}$ & CCGCAAGCTTTAGAGCAAAGCAGGAGCTCCT \\
-2900 & M & $5^{\prime}$ & CCGCCTCGAGGGATCCTTCCAAGGCACTGACC \\
Luc & & $3^{\prime}$ & CCGCAAGCTTAGAGCAAAGCAGGAGCTCCT \\
-351 & H & $5^{\prime}$ & CCGGCTAGCCCATCTCTGGCCTGGCCCTGGG \\
Luc & & $3^{\prime}$ & CCGAAGCTTAGAGGATGAGGTTGGTGAGGGGAC \\
HrII & H & $5^{\prime}$ & CCGGCTAGCGAATATGTTGAAAAGTGCTTGG \\
& & $3^{\prime}$ & CCGGCTAGCCACTCTGTTGGCAAGGTCTTC \\
HrIII & H & $5^{\prime}$ & CCGGCTAGCCCCCATCCCCATGCCTCCAAG \\
& & $3^{\prime}$ & CCGGCTAGCCAGGAGAGCCTGGGGCTCAGT \\
-2218 & H & $5^{\prime}$ & CCGGCTAGCCCCCATCCCCATGCCTCCAAG \\
Luc & & $3^{\prime}$ & GAGTGCAGTGGCGTGATATCTG \\
-2002 & H & $5^{\prime}$ & CCGGCTAGCGGAGCACGTGAGCAGCCCTGGGG \\
Luc & & $3^{\prime}$ & GAGTGCAGTGGCGTGATATCTG \\
-1976 & H & $5^{\prime}$ & CCGGCTAGCGAAGCCGGTTCTCCCACATTCC \\
Luc & & $3^{\prime}$ & GAGTGCAGTGGCGTGATATCTG \\
-1946 & H & $5^{\prime}$ & CCGGCTAGCGGACTGGGTGGAGGGTGTGCC \\
Luc & & $3^{\prime}$ & GAGTGCAGTGGCGTGATATCTG \\
-1906 & H & $5^{\prime}$ & CCGGCTAGCGAGGCCCCCTGAAGGGCTGGGG \\
Luc & & $3^{\prime}$ & GAGTGCAGTGGCGTGATATCTG \\
\hline
\end{tabular}

binding buffer (20 mM HEPES (pH 7.6), $100 \mathrm{mM} \mathrm{KCl}, 1$ $\mathrm{mM}$ DTT, $0.1 \%$ Triton X-100, $2 \mathrm{mM} \mathrm{MgCl}_{2}$ and $20 \%$ glycerol), $3 \mu \mathrm{g}$ of poly(dA-dT) was added to each reaction as nonspecific DNA. For competition assays, 100-fold excess cold oligonucleotides were added to the reaction mix before adding nuclear extracts. The protein-DNA complexes were resolved by gel electrophoresis on $4 \%$ polyacrylamide gels. After electrophoresis, the gels were dried and visualized by autoradiography.

\subsection{DNA constructs and oligonucleotides}

All luciferase constructs were constructed using the pGL3 vector system and were sequence verified before use. Primers used to PCR out DNA regions are in Table 1.

The mouse -2900 Luc and -347 Luc constructs were cloned by PCR amplification of the relevant regions and cloned $\mathrm{I} /$ HindIII into pGL3-basic. The full length human -2872 region was excised from a previous pGL2-backbone construct (described in Neve et al., 2002) using a NheI-HindIII digest and shuttled into pGL3-Basic cut NheI-HindIII to create -2872 Luc. To generate truncations of -2872 Luc the truncated upstream regions were amplified using PCR. All constructs were amplified to include a $3^{\prime} X b a$ I site present at -1792 in the original construct. The PCR fragment and an $X b a \mathrm{I}-H i n d I I I$ fragment contain the proximal promoter and the upstream sequence to -1792 were simultaneously cloned into pGL3-Basic cut NheI-HindIII. HrII and $H r I I I$ were generated using the

A

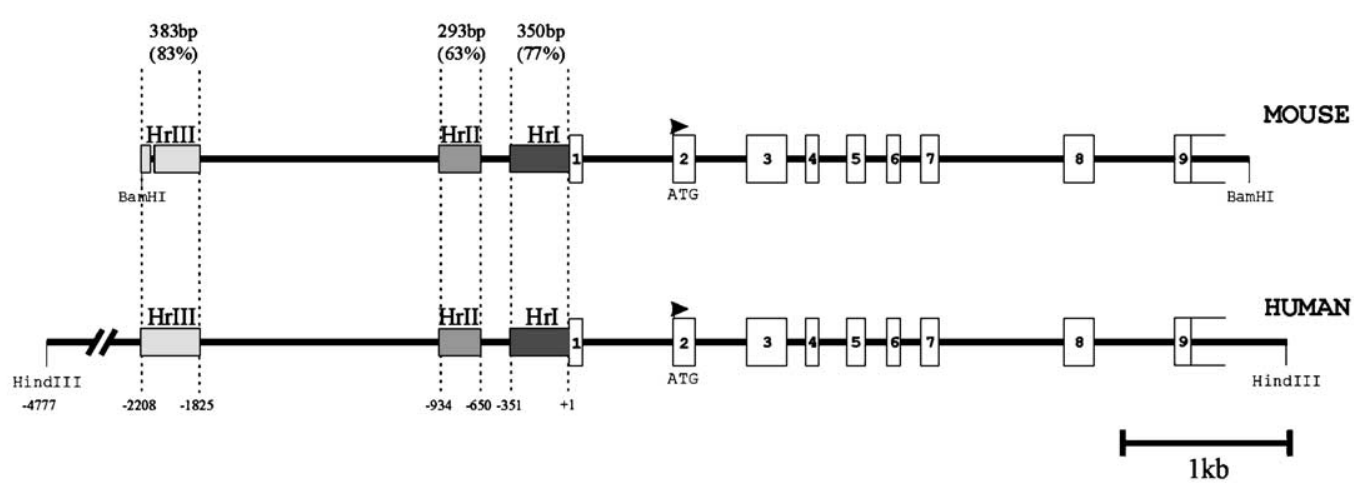

B

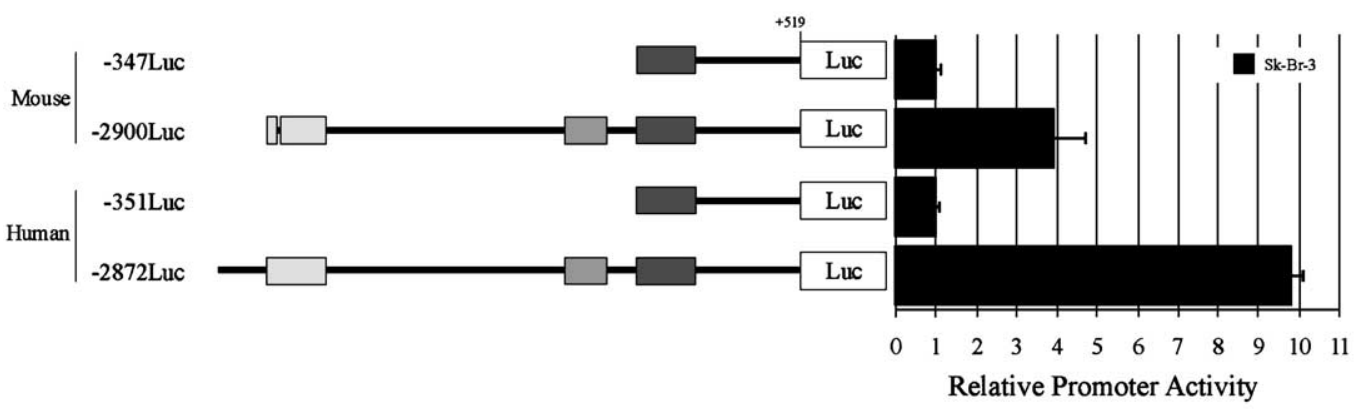

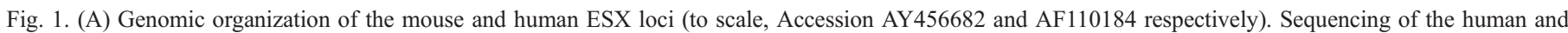

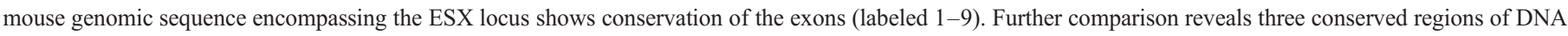

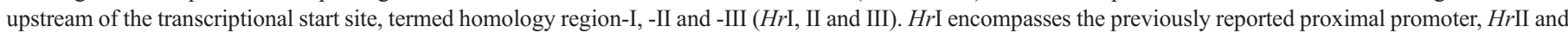

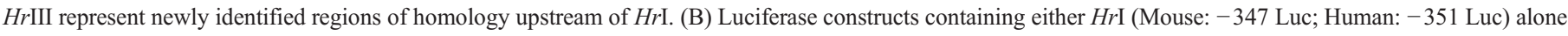

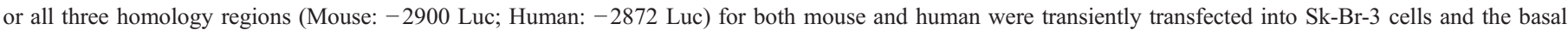

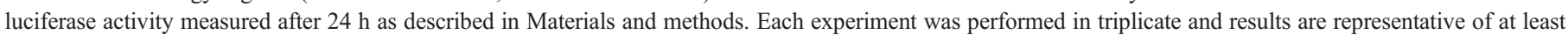
three independent experiments. 
primers in Table 1. A NheI site was generated at either end to clone into -351 Luc or pGL3-Promoter, both cut NheI. Directionality was determined by PCR analysis. All constructs containing the $H r \mathrm{I}$ (proximal promoter) extend to +519 (see Neve et al., 2002).

Cloning of small regions of the putative enhancer elements (-2036-2002;-2002-1976;-1976-1946) was accomplished through annealing of complementary, phosphorylated oligonucleotides with KpnI/NheI overhangs which were cloned into -351 Luc or pGL3-Promoter each cut KpnI/NheI.

\section{Results}

\subsection{Evidence for a cis-acting enhancer element upstream of the ESX gene}

Previously we published the sequence of a 350 bp ESX gene proximal promoter (Neve et al., 1998). Both the mouse and human promoters showed extensive homology (77\% over 350 $\mathrm{bp}$ ) and were serum and mitogen responsive. Alignment of $3 \mathrm{~kb}$ of genomic sequence extending upstream of the proximal promoters of both the mouse and human ESX gene revealed two additional regions of significant homology (termed homology regions II (HrII) and III (HrIII)) in addition to the proximal promoter (termed homology region I $(H r \mathrm{I})$ )(Fig. 1A). HrII and

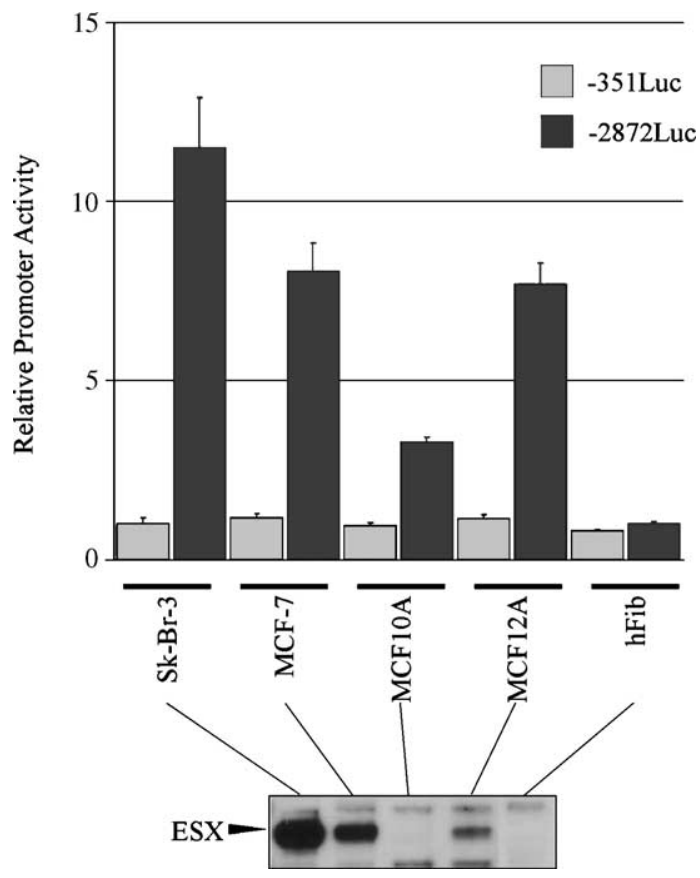

Fig. 2. The upstream enhancer shows epithelial specificity and reflects endogenous ESX protein levels. Transient luciferase assays were used to measure the transcriptional activity of both mouse and human constructs encompassing either the $\mathrm{Hrl}$ (proximal promoter) region or all three homology regions in four human breast epithelial cell lines (Sk-Br-3, MCF-7, MCF10A and $\mathrm{MCF} 12 \mathrm{~A}$ ) and one human fibroblast cell line (hFib). Luciferase assays were performed as described in Materials and methods. Each experiment was performed in triplicate and results are representative of at least three independent experiments. ESX protein levels were determined for each cell line by western analysis of nuclear extracts (lower panel) as described in Materials and methods.
$H r$ III exhibit $83 \%$ homology over 383 bp and $63 \%$ homology over 293 bp, respectively. Mouse and human luciferase reporter constructs containing upstream sequence encompassing all three $\mathrm{Hr}$ regions ( $-2900 \mathrm{Luc}$ and -2872 Luc, respectively) were found to have significantly higher luciferase activity in comparison to the constructs encoding the $\mathrm{HrI}$ ( $-347 \mathrm{Luc}$ and -351 Luc, respectively) alone (Fig. 1B) in the human breast cancer cell line, Sk-Br-3. This suggests the presence of one or more enhancer elements upstream of $\mathrm{Hr} \mathrm{I}$ in both the mouse and human genomes.

The basal activity of the human -2872Luc reporter correlates well with endogenous $E S X$ expression levels in a panel of cell lines (Neve et al., 2002). Comparison of the human -351 Luc with -2872 Luc activity in five untreated epithelial breast cancer cell lines with varying ESX expression levels revealed only the longer construct exhibited activity that varied in conjunction with the basal ESX level of each cell line (from barely detectable levels in MCF10a cells to highly expressed levels in Sk-Br-3 cells). This implies the upstream sequence of the ESX promoter likely contains a cis-acting enhancer region controlling cell-to-cell variation in endogenous ESX expression (Fig. 2). Since $E S X$ expression is restricted to epithelial cells (Andreoli et al., 1997; Chang et al., 1997; Oettgen et al., 1997; Tymms et al., 1997), it is likely that this cis-acting enhancer region contains an epithelial-specific response element.

\subsection{ESX expression is regulated by an epithelial-specific enhancer element}

To determine whether either $\mathrm{HrII}$ or $\mathrm{HrIII}$ of the human gene contained the putative enhancer element, each region was independently cloned upstream of the ESX proximal promoter driving luciferase expression ( $-351 \mathrm{Luc})$. HrII had no effect on -351 Luc transcriptional activity, while $H r$ III enhanced the proximal promoter activity to levels equivalent to the entire upstream sequence, regardless of its orientation (Fig. 3A). HrIII also significantly enhanced the activity of a heterologous SV40 promoter when introduced into Sk-Br-3 cells but not upon transfection into human fibroblasts (Fig. 3B). Taken together, these results suggest that $H r I I I$ alone contains an epithelialspecific enhancer element. To determine the minimal element required for this full enhancer activity, we compared the luciferase activity of sequentially truncated promoter constructs (Fig. 3C). Initial experiments indicated that the enhancer lays between $-2036 \mathrm{bp}$ and $-1819 \mathrm{bp}$ within $\mathrm{HrIII}$ (not shown). Further deletions of the $5^{\prime}$ sequence identified a 30 bp ESX enhancer sequence (EES) ( -1976 bp to -1946 bp) within $\mathrm{HrIII}$ which is required for full activity of $\mathrm{HrIII}$ (Fig. 3C, top panel). All constructs transfected into human fibroblasts exhibited promoter activity equivalent to the proximal promoter (-341 Luc), confirming the lack of significant EES enhancer activity in nonepithelial cells (Fig. 3C, lower panel).

Sequence comparison of the human and mouse $\mathrm{Hr}$ III regions revealed several clusters of conserved putative transcription factor-binding sites, several Ikaros isoforms localized to the EES are depicted (Fig. 4A) (Quandt et al., 1995). Consistent 
A

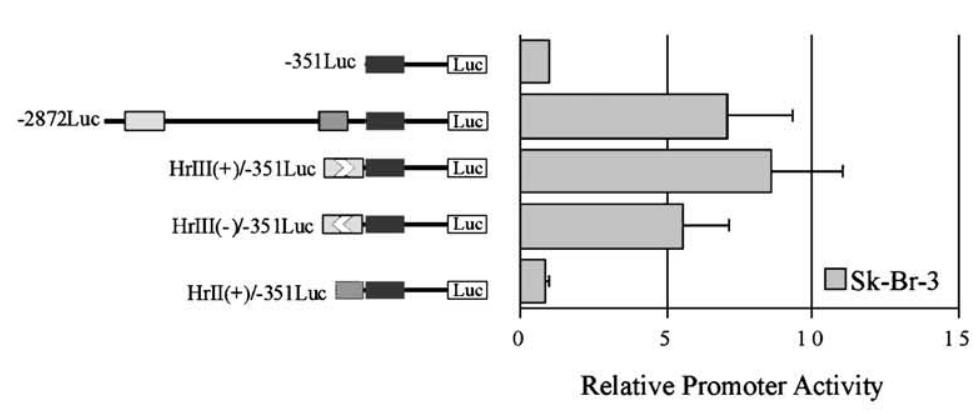

B

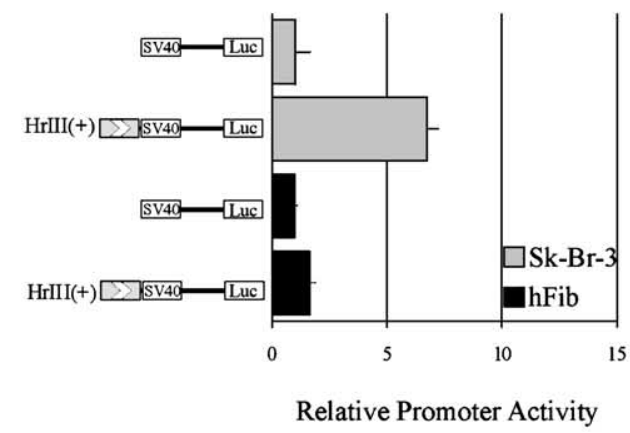

C
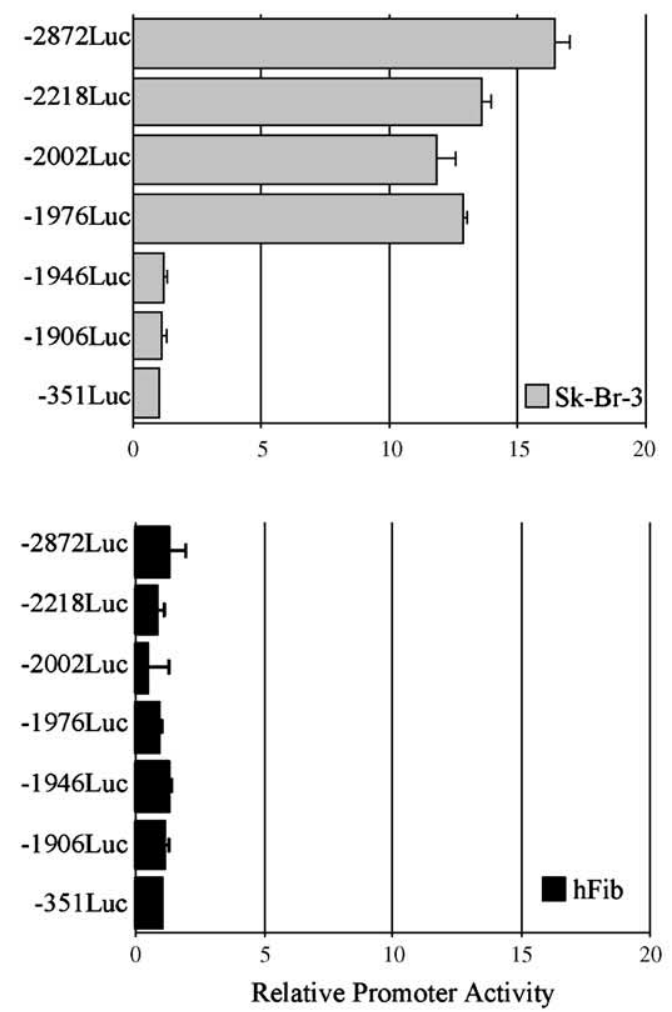

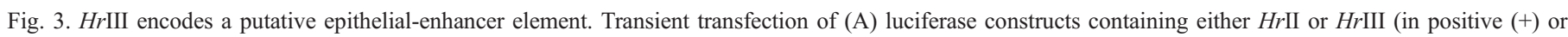

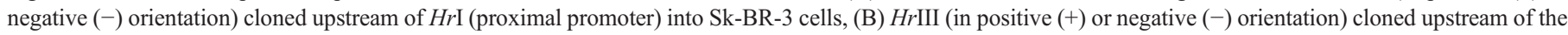

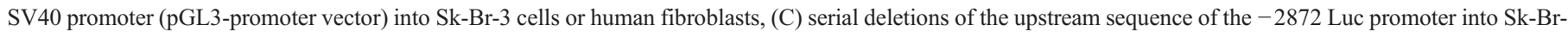

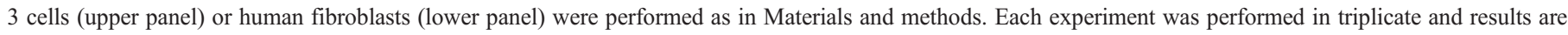
representative of at least three independent experiments.

with the deletion constructs, the EES (-1976bp to $-1946 \mathrm{bp})$ is sufficient for full enhancer activity when placed upstream of the -341 Luc promoter construct, independent of orientation (Fig. 4B). Similarly, when a single copy of the EES was placed upstream of the heterologous SV40 promoter a ten-fold enhancement of basal promoter activity is observed (Fig. 4C). Three tandem copies of the EES sequentially arranged upstream of the SV40 promoter increases basal promoter activity more than 60-fold (Fig. 4C). In keeping with the putative epithelial specificity of the EES, none of the $H r$ III constructs affect promoter activity when introduced into human fibroblasts (Fig. 4C).

\subsection{An EES binding complex (EBC) controls ESX enhancer activity}

EMSA assays, using radiolabelled oligonucleotides corresponding to the EES sequence, revealed two EES-binding protein complexes. While both protein-DNA complexes were specifically competed by excess, unlabelled EES oligonucleotide $(100 \times$ EES $)$, the slower-migrating complex was completely competed away in contrast to minimal competition of the faster migrating (non-specific) complex (Fig 4D, right panel, lane 2). This indicates a direct relationship between EES-binding EBC activity, the magnitude of EES trans-activation potential, and endogenous ESX protein expression among various cell lines. The EBC EMSA data are consistent with the promoter-reporter studies and argue that EES constitutes the core enhancer element within the HrIII and likely determines the relative level of $E S X$ transcription in any given epithelial cell.

\subsection{EBC formation is dependent on epithelial differentiation signals}

Since $E S X$ expression is restricted to epithelial tissues and is involved in epithelial differentiation (Oettgen et al., 1997; Brembeck et al., 2000; Yoshida et al., 2000; Kim et al., 2002; $\mathrm{Ng}$ et al., 2002) we tested whether epithelial differentiation is associated with EBC binding to the EES, as detected by EMSA. We have shown ESX is up-regulated in HC11 cells during lactogenic competency in the presence of growth factors (Neve et al., 1998). Using this cell system, we observe that the EBC-EES complex was induced upon reaching lactogenic competency (Fig. 5, lanes 2-4). Since our ESX c-terminalspecific antisera does not cross-react with murine $E S X$, we were unable to determine ESX protein levels in these mouse cells; however, RT-PCR analysis showed an increase in ESX mRNA levels, consistent with the EMSA result (Fig. 5A). To test how the EBC activity is affected by differentiation signals, the breast cancer epithelial cell line, MCF-7, was used a model 
A

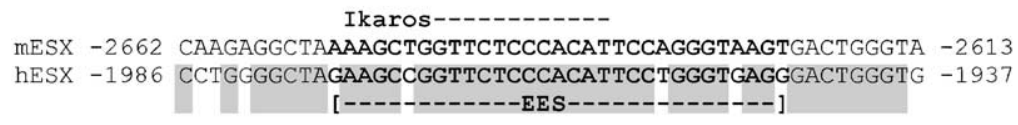

B

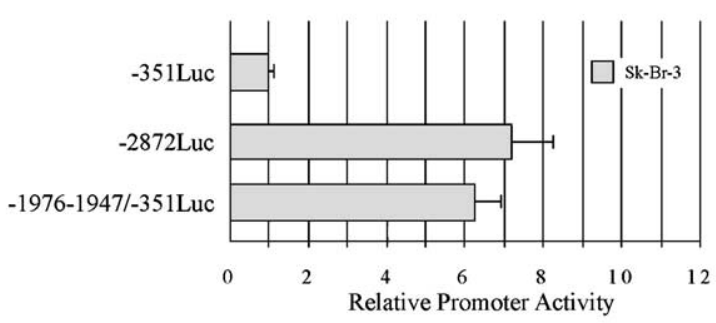

C

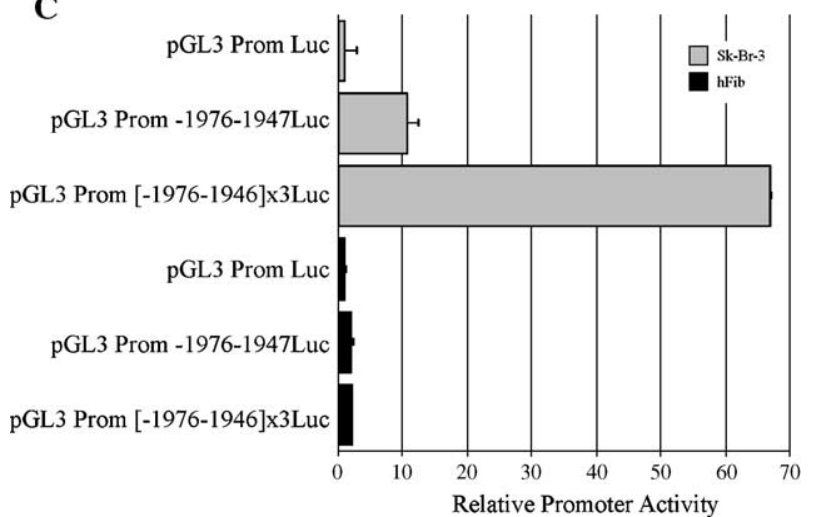

D

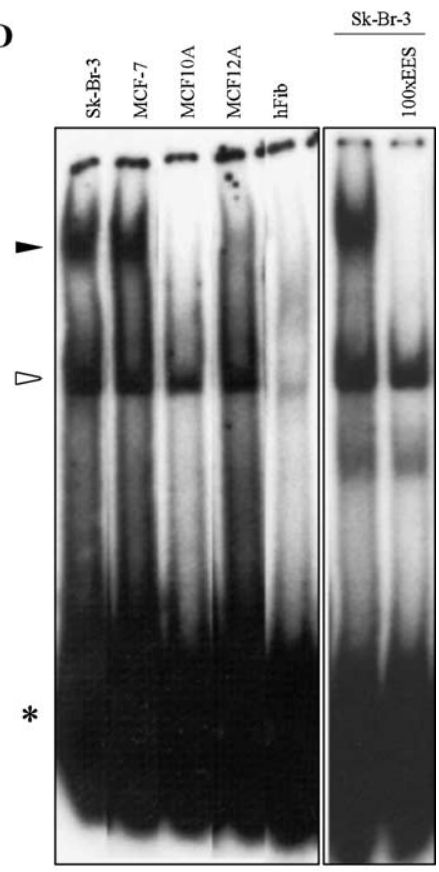

Fig. 4. A conserved $30 \mathrm{bp}$ epithelial enhancer element controlling ESX expression. (A) Sequence comparison of $H r I I I$ between mouse and human. Alignment of mouse and human HrIII regions, overall homology with the EES enhancer sequence indicated in bold. Shaded regions indicate perfect homology between the two sequences. Putative transcription factor binding sites are indicated above the sequence alignment. (B) Transient transfections of the EES cloned upstream of the $H r \mathrm{I}$

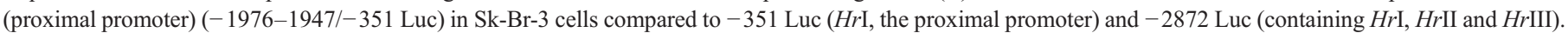
(C) Transient transfection of the EES and three tandem copies of the EES placed upstream of the SV40 promoter (pGL3 Promoter) in Sk-Br-3 cells and human fibroblasts. Transient transfections are described in the Materials and methods and each experiment was performed in triplicate and results are representative of at least three independent experiments. (D) Electromobility shift assays (EMSA) showing nuclear factors binding the EES. Nuclear extracts from four epithelial cell lines and one human fibroblast cell line, with differing levels of ESX protein were analysed for DNA-protein complex formation. Results are reflective of several independent experiments. *=unbound probe; filled arrow $=$ specific band shift; open arrow=non-specific band.

system, since it undergoes differentiation in response to retinoic acid (RA) (Wang et al., 2000). We found that RA treatment induced endogenous ESX mRNA and protein levels and increased EES-protein complex within $1 \mathrm{~h}$ (Fig 5A, lanes 5-6). The transcriptional up-regulation of ESX was dependent on denovo RNA synthesis, since treatment of MCF-7 cells with RA in the presence of actinomycin D prevented an increase in ESX mRNA levels and ESX protein levels. These results confirm that binding of EBC to EES appears responsive to epithelial differentiation signals and may mediate the observed up-regulation of ESX expression that occurs during mammary gland development and tumorigenesis.

\section{Discussion}

Epithelial cells play a critical role in the development and homeostasis of many organs. The same mechanisms controlling normal epithelial processes are often found perturbed in human disease such as cancer. However, there is very little information regarding the control of genes, especially transcription factors, regulating epithelial differentiation and maintenance. ESX is clearly involved in the development, differentiation and carci- nogenesis of epithelial organs including the mammary gland, however, ESX gene targets and mechanisms of action remain elusive. Here we report the cis-acting regulatory elements that control the expression of human ESX.

We previously isolated and sequenced the mouse and human ESX loci and reported on the transcriptional activity of the ESX proximal promoter (Neve et al., 1998). The proximal promoter element and genomic organization of ESX was subsequently described (Oettgen et al., 1999). Comparison of the human and mouse upstream genomic sequences has revealed two additional regions of high homology, and detailed analysis of these regions now reveals an upstream enhancer region bearing a 30 base pair minimal enhancer element. This newly identified upstream enhancer element described here and termed EES, exhibits epithelial-specific activity when transfected into a panel of epithelial and non-epithelial cell lines. This activity correlates with endogenous levels of ESX in these cells. In contrast, the proximal promoter element shows similar basal activity in all cell lines tested. These observations suggest that endogenous transcription factors capable of binding to the EES during unstressed conditions are restricted to epithelial cells and positively control ESX expression. In all experiments this 
A

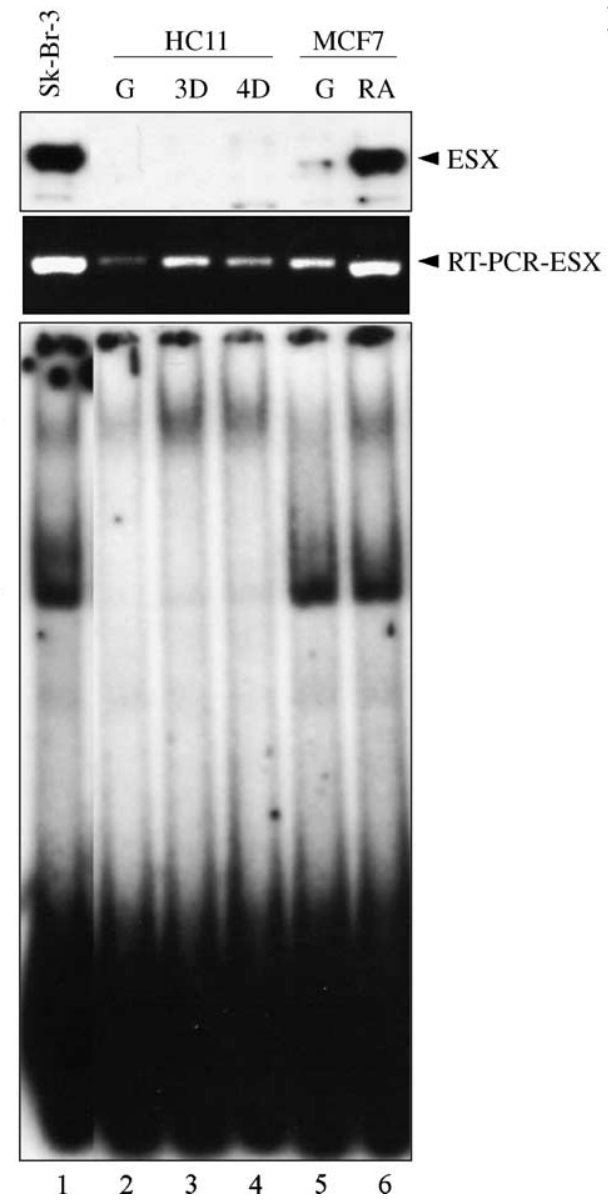

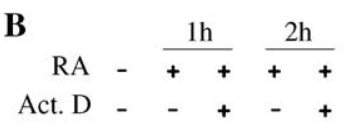

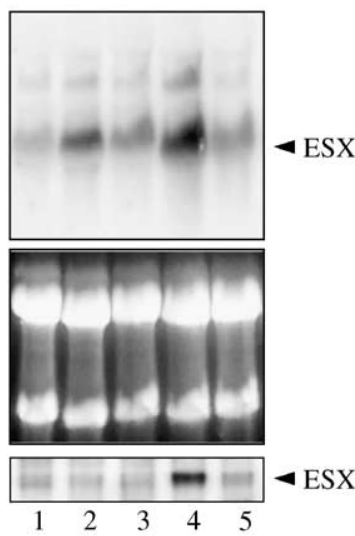

MCF-7

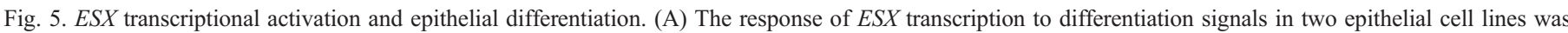

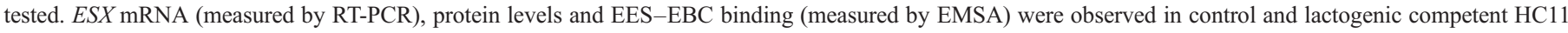

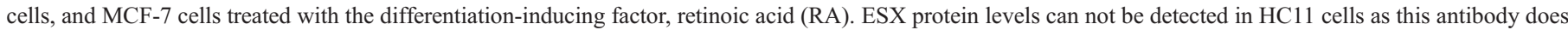

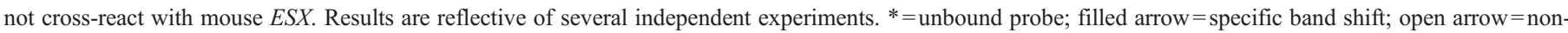

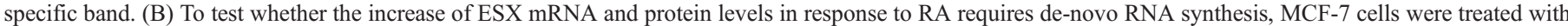

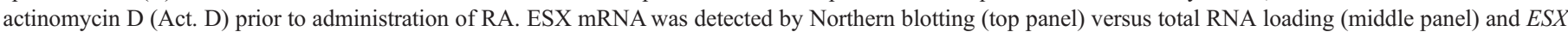

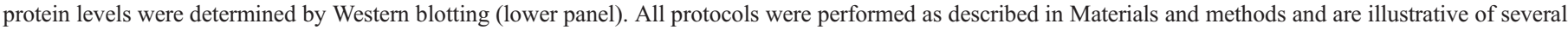
independent experiments. $\mathrm{G}=$ growing; $3 \mathrm{D}=$ cells at 3 days confluent; $4 \mathrm{D}=$ cells at 4 days confluent.

complex associated with the EES and correlated well with endogenous ESX expression levels in control cells and in differentiating mouse and human epithelial cells.

The EES element is distinct from one identified by Park et al. in the $E S X$ proximal promoter region in human gastric cancers (Park et al., 2001). We found no significant enhancer binding activity using their DNA binding motif to probe our panel of breast cancer cell lines (not shown). Recently a mouse enhancer element was identified (Hou et al., 2004) which is distinct from the EES. We have found that the mouse enhancer, which is not present in the human $E S X$ gene, is not functional in Sk-Br-3 cells; whereas the human ESX enhancer exhibits weak, but significant, activity in mouse F9 differentiated cells (Rizzino, unpublished data). Overall this points to a complex regulation of $E S X$ that is species-dependent and organ-dependent within a species.

One hallmark of cancer is a loss of cell differentiation (Tenen, 2003). ESX plays roles in epithelial differentiation including that of primary human mammary epithelial cells in vitro and during in vivo normal mammary gland development and breast tumorigenesis (Neve et al., 1998, 2002). Our data suggests that increased ESX expression in breast epithelial cells decreases cellular proliferation (Neve, unpublished data), which appears contrary to the function of a cancer-related gene, but is in keeping with its regulatory role during mammary gland development. Indeed, reports indicate potential transforming and apoptotic roles for $E S X$ under specific biological conditions (Prescott et al., 2004; Schedin et al., 2004). We have previously shown that transcriptional up-regulation of $E S X$ is downstream of ErbB receptor activation, primarily mediated by $\mathrm{PI} 3 \mathrm{~K} / \mathrm{PKB}$ rather than MAPK signaling (Neve et al., 2002); and thus it is possible that oncogene-associated up-regulation of $E S X$ is necessary to confer cancer-defining cell behavior such as invasiveness and metastatic potential rather than proliferation. Of note in this regard, TGF- $\beta$ RII is a transcriptional target of ESX (Choi et al., 1998; Kim et al., 2002), and co-activation of TGF- $\beta$ signaling in conjunction with ErbB2/neu activation has recently been shown to confer an anti-mitogenic but pro-metastatic 
phenotype (Muraoka et al., 2003; Siegel et al., 2003). By identifying a critical genetic regulatory element that controls $E S X$ expression in an epithelial-and tissue-specific manner we have uncovered a key mechanism potentially common to both normal epithelial development and carcinogenesis; as such, future identification of the components of $\mathrm{EBC}$ may yield new breast cancer therapeutic targets.

\section{Acknowledgements}

We thank Dr. Yinghui Guan, UCSF, for helpful suggestions and critical review of the manuscript.

R.M.N. was supported in part by a fellowship from the Breast Cancer Fund of the State of California through the Breast Cancer Research Program of the University of California, Grant 7BF-0027. This work was supported in part by NIH sponsored grant R01-CA36773 as well as the Hazel P. Munroe Memorial Fund.

\section{References}

Andreoli, J.M., Jang, S.I., Chung, E., Coticchia, C.M., Steinert, P.M., Markova, N.G., 1997. The expression of a novel, epithelium-specific Ets transcription factor is restricted to the most differentiated layers in the epidermis. Nucleic Acids Res. 25, 4287-4295.

Brembeck, F.H., Opitz, O.G., Libermann, T.A., Rustgi, A.K., 2000. Dual function of the epithelial specific Ets transcription factor, ELF3, in modulating differentiation. Oncogene 19, 1941-1949.

Chang, C.H., et al., 1997. ESX: a structurally unique Ets overexpressed early during human breast tumorigenesis. Oncogene 14, 1617-1622.

Chang, C.H., Scott, G.K., Baldwin, M.A., Benz, C.C., 1999. Exon 4-encoded acidic domain in the epithelium-restricted Ets factor, $E S X$, confers potent transactivating capacity and binds to TATA-binding protein (TBP). Oncogene 18, 3682-3695.

Choi, S.G., et al., 1998. A novel Ets-related transcription factor, ERT/ESX/ESE1 , regulates expression of the transforming growth factor-beta type II receptor. J. Biol. Chem. 273, 110-117.

Dignam, J.D., Martin, P.L., Shastry, B.S., Roeder, R.G., 1983. Eukaryotic gene transcription with purified components. Methods Enzymol. 101, 582-598.

Dittmer, J., Nordheim, A., 1998. Ets transcription factors and human disease. Biochim. Biophys. Acta 1377, F1-F11.

Eckel, K.L., Tentler, J.J., Cappetta, G.J., Diamond, S.E., Gutierrez-Hartmann, A., 2003. The epithelial-specific Ets transcription factor $E S X / \mathrm{ESE}-1 / \mathrm{Elf}-3$ modulates breast cancer-associated gene expression. DNA Cell Biol. 22, 79-94.

Hou, J., Wilder, P.J., Bernadt, C.T., Boer, B., Neve, R.M., Rizzino, A., 2004. Transcriptional regulation of the murine Elf3 gene in embryonal carcinoma cells and their differentiated counterparts: requirement for a novel upstream regulatory region. Gene 340, 123-131.

Kim, J.H., Wilder, P.J., Hou, J., Nowling, T., Rizzino, A., 2002. Activation of the murine type II transforming growth factor-beta receptor gene: upregulation and function of the transcription factor Elf-3/Ert/ESX/Ese-1. J. Biol. Chem. 277, 17520-17530.

Kwon, J.H., Keates, S., Simeonidis, S., Grall, F., Libermann, T.A., Keates, A.C., 2003. ESE-1, an enterocyte-specific Ets transcription factor, regulates MIP- 3alpha gene expression in Caco-2 human colonic epithelial cells. J. Biol. Chem. 278, 875-884

Muraoka, R.S., et al., 2003. Increased malignancy of neu-induced mammary tumors overexpressing active transforming growth factor beta1. Mol. Cell. Biol. 23, 8691-8703.

Neve, R., et al., 1998. The epithelium-specific Ets transcription factor ESX is associated with mammary gland development and involution. FASEB J. 12, $1541-1550$

Neve, R.M., Ylstra, B., Chang, C.H., Albertson, D.G., Benz, C.C., 2002. ErbB2 activation of ESX gene expression. Oncogene 21, 3934-3938.

$\mathrm{Ng}$, A.Y., et al., 2002. Inactivation of the transcription factor Elf3 in mice results in dysmorphogenesis and altered differentiation of intestinal epithelium. Gastroenterology 122, 1455-1466.

Oettgen, P., et al., 1997. Isolation and characterization of a novel epitheliumspecific transcription factor, ESE-1, a member of the Ets family. Mol. Cell. Biol. 17, 4419-4433.

Oettgen, P., Barcinski, M., Boltax, J., Stolt, P., Akbarali, Y., Libermann, T.A., 1999. Genomic organization of the human ELF3 (ESE-1/ESX) gene, a member of the Ets transcription factor family, and identification of a functional promoter. Genomics 55, 358-362.

Park, S.H., Kim, Y.S., Park, B.K., Hougaard, S., Kim, S.J., 2001. Sequencespecific enhancer binding protein is responsible for the differential expression of ERT/ESX/ELF-3/ESE-1/jen gene in human gastric cancer cell lines: implication for the loss of TGF-beta type II receptor expression. Oncogene 20, 1235-1245.

Prescott, J.D., Koto, K.S., Singh, M., Gutierrez-Hartmann, A., 2004. The Ets transcription factor ESE-1 transforms MCF-12A human mammary epithelial cells via a novel cytoplasmic mechanism. Mol. Cell. Biol. 24, 5548-5564.

Quandt, K., Frech, K., Karas, H., Wingender, E., Werner, T., 1995. MatInd and MatInspector: new fast and versatile tools for detection of consensus matches in nucleotide sequence data. Nucleic Acids Res. 23, 4878-4884.

Remy, P., Baltzinger, M., 2000. The Ets-transcription factor family in embryonic development: lessons from the amphibian and bird. Oncogene 19, 6417-6431.

Rudders, S., et al., 2001. ESE-1 is a novel transcriptional mediator of inflammation that interacts with NF-kappa B to regulate the inducible nitricoxide synthase gene. J. Biol. Chem. 276, 3302-3309.

Schedin, P.J., et al., 2004. ESX induces transformation and functional epithelial to mesenchymal transition in MCF-12A mammary epithelial cells. Oncogene 23, 1766-1779.

Sharrocks, A.D., 2001. The Ets-domain transcription factor family. Nat. Rev., Mol. Cell Biol. 2, 827-837.

Siegel, P.M., Shu, W., Cardiff, R.D., Muller, W.J., Massague, J., 2003. Transforming growth factor beta signaling impairs Neu-induced mammary tumorigenesis while promoting pulmonary metastasis. Proc. Natl. Acad. Sci. U. S. A. 100, 8430-8435.

Tenen, D.G., 2003. Disruption of differentiation in human cancer: AML shows the way. Nat. Rev., Cancer 3, 89-101.

Tymms, M.J., et al., 1997. A novel epithelial-expressed Ets gene, ELF3: human and murine cDNA sequences, murine genomic organization, human mapping to $1 \mathrm{q} 32.2$ and expression in tissues and cancer. Oncogene 15, 2449-2462

Wang, Q., Yang, W., Uytingco, M.S., Christakos, S., Wieder, R., 2000. 1,25Dihydroxyvitamin D3 and all-trans-retinoic acid sensitize breast cancer cells to chemotherapy-induced cell death. Cancer Res. 60, 2040-2048.

Yoshida, N., Yoshida, S., Araie, M., Handa, H., Nabeshima, Y., 2000. Ets family transcription factor ESE-1 is expressed in corneal epithelial cells and is involved in their differentiation. Mech. Dev. 97, 27-34. 